\title{
PEMISAHAN PIGMEN PADA MIKROALGA Dunaliella salina YANG TELAH DIBERI SENYAWA TIMBAL ASETAT
}

\author{
(Separation Pigment Microalgae Dunaliella salina Which has been Lead \\ Acetate Compound)
}

\author{
Greisela Y. Balaira ${ }^{{ }^{*}}$, Kurniati Kemer ${ }^{1}$, Desy M H. Mantiri ${ }^{1}$.
}

1. Program Studi IImu Kelautan, Fakultas Perikanan dan IImu Kelautan, Universitas Sam Ratulangi, Manado.

*e-mail : chellabalaira@yahoo.co.id

Dunaliella salina is one of the micro-algae are quite widely studied primarily as a source of $\beta$-carotene and glycerol. Utilization Dunaliella quite diverse which is as a health food as it has been marketed in the developed countries. This microalgae is one marine organism that is susceptible to changes or ecological pressure so that the main target exposed to contaminants such as heavy metals and so forth. The aim of this study to determine how the effects of lead acetate compound of the pigment content of microalgae Dunaliella and the types of carotenoid pigments contained in the micro-alga Dunaliella salina. The results obtained in this study is the compounds of Lead acetate given can reduce the concentration of chlorophyll pigments on day 8 , but the chlorophyll pigment concentration at day 14 increased extraction of the container by the lead compounds. This is because the container of day 14 Dunaliella salina retain life by increasing the concentration of chlorophyll pigments. Results from TLC analysis indicated that there were three fractions in yellow, which is the fraction 1 with Pigment type of $\beta$-carotene, the fraction 4 with a type of pigment types of zeaxanthin and a fraction to 5 with the type of pigment types alloxanthin. This is because the micro-alga Dunaliella salina has carotenoid pigments abundantly.

Keyword: Dunaliella salina, Lead acetate, Pigments, TLC

Dunaliella salina merupakan salah satu mikro alga yang cukup banyak diteliti terutama sebagai sumber $\beta$-karoten dan gliserol. Pemanfaatan Dunaliella cukup beragam salasatunya sebagai makanan kesehatan seperti yang telah dipasarkan di Negara-negara maju. Mikro alga ini merupakan salah satu organisme laut yang rentan terhadap perubahan atau tekanan ekologis sehingga menjadi sasaran utama terkena bahan-bahan pencemar seperti logam berat dan lain sebagainya. Penelitian ini bertujuan untuk mengetahui bagaimana pengaruh senyawa timbal asetat terhadap kandungan pigmen dari mikro alga Dunaliella serta jenis-jenis pigmen karotenoid yang terkandung pada mikro alga Dunaliella salina. Hasil yang diperoleh dalam penelitian ini adalah Pemberian senyawa Timbal asetat dapat menurunkan konsentrasi pigmen klorofil pada hari ke 8, Namun pada konsentrasi pigmen klorofil pada ekstraksi hari ke 14 meningkat pada wadah yang diberi dengan senyawa timbal. Hal ini dikarenakan pada wadah hari ke 14 Dunaliella salina mempertahakan hidup dengan meningkatkan konsentrasi pigmen klorofil. Hasil dari analisis KLT menujukan ada 3 fraksi dengan warna kuning, yaitu fraksi 1 dengan jenis Pigem $\beta$-karoten, fraksi 4 dengan jenis pigmen tipe zeaxanthin dan fraksi ke 5 dengan jenis pigmen tipe alloxanthin $\mathrm{Hal}$ ini disebabkan karena pada mikro alga Dunaliella salina memiliki pigmen karotenoid yang melimpah.

Kata Kunci : Dunaliella salina, Timbal asetat, Pigmen, KLT 


\section{PENDAHULUAN}

Menurut Evo (2001) pengertian laut dalam bahasa Indonesia yaitu kumpulan air asin dalam jumlah yang banyak dan luas yang menggenangi dan membagi daratan atas benua atau pulau. Indonesia memiliki wilayah perairan laut yang sangat luas, ditunjang oleh iklim tropis sehingga menjadikan perairan Indonesia sangat kaya akan sumber daya lautnya terlebih lagi terkenal dengan keragamannya yang memiliki warna-warni yang sangat indah. Warna yang indah tersebut disebabkan oleh adanya pigmen yang terkandung dalam tubuh organisme (Wijaya, 2004). Goodwin (1980) mengatakan, bahwa pigmen merupakan biokrom (warna hidup) yang ditemukan tersebar di permukaan bumi pada berbagai jenis tumbuhan dan hewan, pigmen pada hewan masuk melalui makanan.

Salah satu sumber daya laut yang penting untuk dikaji adalah alga. Alga merupakan salah satu sumber daya hayati laut yang bernilai ekonomi dan memiliki manfaat yang baik untuk manusia dan lingkungan sekitarnya, misalnya sebagai bahan makanan, bahan dasar kosmetik, dan bahan pembuatan obat (Ratri $d k k, 2003$ ). Menurut Bold dan Wynne (1985) mikroalga diklasifikasikan dalam delapan kelas yaitu Chlorophyceae (alga hijau), Cyanophyceae (alga hijau-biru), Rhodophyceae (alga merah), Bacillariophyceae (diatom), Chrysophyceae (alga emas), Pyrhophyceae (alga api), Xanthophyceae (hijau kuning) dan Euglenophyceae (euglena). Setiap kelas alga memiliki ciri warna tertentu, karena adanya jenis pigmen yang dikandungnya. Jenis pigmen yang banyak ditemukan pada alga adalah pigmen klorofil dan karotenoid (Jupin dan Lamant, 1999).

Dunalella salina merupakan salah satu mikro alga yang cukup banyak diteliti terutama sebagai sumber $\beta$-karoten dan gliserol. Pemanfaatan
Dunaliella cukup beragam sala satunya sebagai makanan kesehatan seperti yang telah dipasarkan di negara-negara maju. Mikro alga ini merupakan salah satu organisme laut yang rentan terhadap perubahan atau tekanan ekologis sehingga menjadi sasaran utama terkena bahan-bahan pencemar seperti logam berat dan lain sebagainya, sehingga perlu diadakan penelitian untuk mengetahui bagaimana pengaruh senyawa timbal asetat terhadap kandungan pigmen dari mikro alga Dunaliella serta jenis-jenis pigmen karotenoid yang terkandung pada mikro alga $D$. salina.

\section{METODOLOGI PENELITIAN}

Alga mikro yang digunakan adalah jenis $D$. salina, dalam penelitian ini di ambil atau dipesan dari Balai Besar Perikanan Budidaya Air Payau yang ada di Jepara, kemudian dikultur pada ruang kultur dengan suhu $25^{\circ} \mathrm{C}$ dan penyinaran lampu tabung 48 watt di Laboratorium Teknologi Akuakultur FPIK-UNSRAT.

Air laut yang digunakan sebagai medium alga disaring menggunakan kertas saring milipore $0,45 \mu \mathrm{m}$ dengan bantuan aspirator dan di sterilisasi dengan autoclave agar air laut steril. Kemudian air laut yang sudah disterilkan ditambahkan nutrien berupa campuran larutan conway yang belum berisikan mikro alga dan diaduk hingga merata. Kemudian air laut yang sudah tercampur dengan conway dibagikan kedalam 4 labu erlemeyer dan ditambahkan mikro alga $D$. salina yang selanjutnya disimpan kedalam lemari kultur.

Pemberian senyawa timbal asetat di lakukan setelah medium alga telah siap dengan campuran larutan Conway dan mikro alga $D$. salina, selanjutnya diberi dengan perlakuan senyawa Timbal asetat dengan konsentrasi 1 ppm, 2 ppm, 3 ppm dan 1 kontrol. 
Pengamatan terhadap jumlah populasi sel $D$. salina dilakukan setiap hari pada jam yang sama. Diambil 0,5 $\mathrm{ml}$ sampel untuk menghitung kepadatan dari alga dengan menggunakan haemositometer.

Ektraksi pigmen dilakukan dengan menggunakan metode Harbone (1987) sampel alga mikro D. salina yang telah disentrifus pada kecepatan 3000 rpm selama 10 menit diekstraksi dalam ruangan dingin tanpa cahaya. Alga diaduk dalam larutan aseton 100\% sebanyak $2 \mathrm{ml}$. sampel yang berwarna hijau tersebut dimasukan dalam labu pemisah selanjutnya dipisahkan dengan pelarut organik melalui metode Pratt (1994). Tambahkan larutan organik petroleum eter $4 \mathrm{ml}$, kemudian ditambahkan aquades sebanyak $10 \mathrm{ml}$ diamkan sampai terlihat 2 lapisan, Lapisan atas : hijau muda dalam PE, Lapisan bawah: hydro aseton (putih keruh)

Lapisan bawah yang berwarna putih keruh dalam hydro aseton di buang, selanjutnya ambil lapisan atas. Pada tahap ini telah didapat pigmen yang bersih dari aseton. Hanya lapisan atas yang akan dianalisis dengan menggunakan KLT dan spektrofotometer dapat menentukan jenis pigmen.

\section{HASIL DAN PEMBAHASAN}

Kepadatan sel-sel $D$. salina dihitung mulai dari tanggal 10 September 2016 sampai pada tanggal 23 September 2016. Dalam penelitian ini $D$. salina diberi perlakuan dengan senyawa timbal asetat selama 14 hari dengan 2 tahapan ekstraksi yaitu ekstrak pada tahap eksponensial dan ekstrak pada tahap kematian pada hari ke 14. Tahap eksponensial berada pada hari ke 8 di ketahui pada wadah kontrol. Pada hari ke 9 alga sudah mengalami penurunan jumlah sel sehingga pada hari itu juga sudah dilakukan ektraksi pigmen tahap pertama, kemudian yang 4 wadah sisa diteruskan sampai pada tahap kematian yaitu pada hari ke 14 .

$$
\text { Hasil kurva (Gambar 1) }
$$

menunjukkan pada wadah kontrol, fase eksponensial terjadi pada hari ke 7 kemudian diikuti tahap stationer sampai pada hari ke 8, sehingga dilakukan ekstraksi sampel tahap pertama pada hari tersebut. Jumlah kepadatan spektrofotometer, karena pada lapisan ini terdapat pigmen klorofil dan karotenoid. Nilai-nilai tertinggi (kepadatan optik) dan bentuk kurva yang diperoleh dengan wadah kontrol adalah $19 \times 10^{6} \mathrm{sel} / \mathrm{ml}$, kepadatan pada wadah uji yang diberi senyawa timbal 1 $\mathrm{ppm}$ adalah $6 \times 10^{6} \mathrm{sel} / \mathrm{ml}$, wadah uji timbal $2 \mathrm{ppm}$ adalah $5 \times 10^{6} \mathrm{sel} / \mathrm{ml}$ dan pada wadah $3 \mathrm{ppm}$ mengalami penurunan pada jumlah kepadatan yaitu $4 \times 10^{6} \mathrm{sel} / \mathrm{ml}$.

Jika dibandingkan dengan kontrol, pertumbuhan alga yang diberi perlakuan senyawa Timbal asetat dengan konsentrasi 1 ppm, 2 ppm, dan 3 ppm mengalami Penurunan mulai dari hari pertama hingga hari ke 8. Dari hasil perhitungan kepadatan terhadap pertumbuhan mikro alga $D$. salina dari masing-masing perlakuan dengan konsentrasi 1 ppm, 2 ppm, 3 ppm dan kontrol sangat berbeda nyata, dimana perlakuan pemberian senyawa timbal dengan konstrasi 3 ppm dapat mengurangi jumlah sel lebih banyak dibanding dengan perlakuan dengan konsentrasi 1 ppm dan 2 ppm.

Penurunan jumlah sel disebabkan karena logam berat sangat beracun bagi mikroalga dan dapat menghambat pertumbuhan sel apabila diberikan dalam jumlah yang berlebihan (Wong dkk, 1995).

Berdasarkan grafik yang ditunjukan pada Gambar 2, dapat diketahui bahwa waktu pertumbuhan yang dibutuhkan oleh $D$. salina untuk beradaptasi terhadap medium alga cukup singkat, yakni 2 hari. Hal ini dapat dilihat pada grafik kepadatan sel pada wadah kontrol, 2 ppm dan 3 ppm. dimana kepadatan sel pada hari pertama dan kedua belum menunjukan 


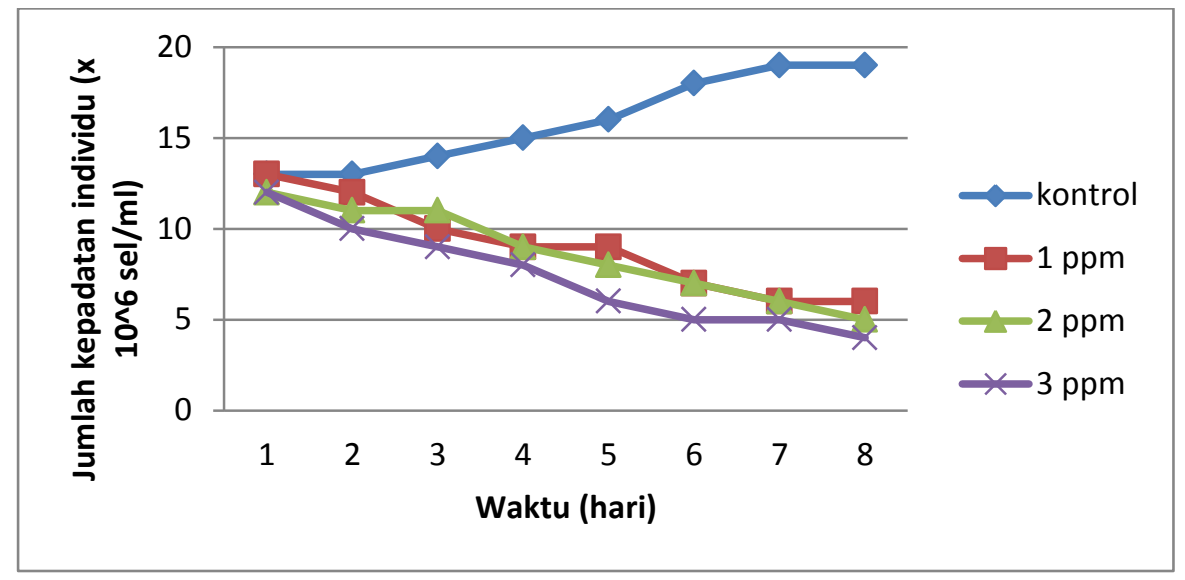

Gambar 1. Grafik Pertumbuhan D. salina Hari ke-8

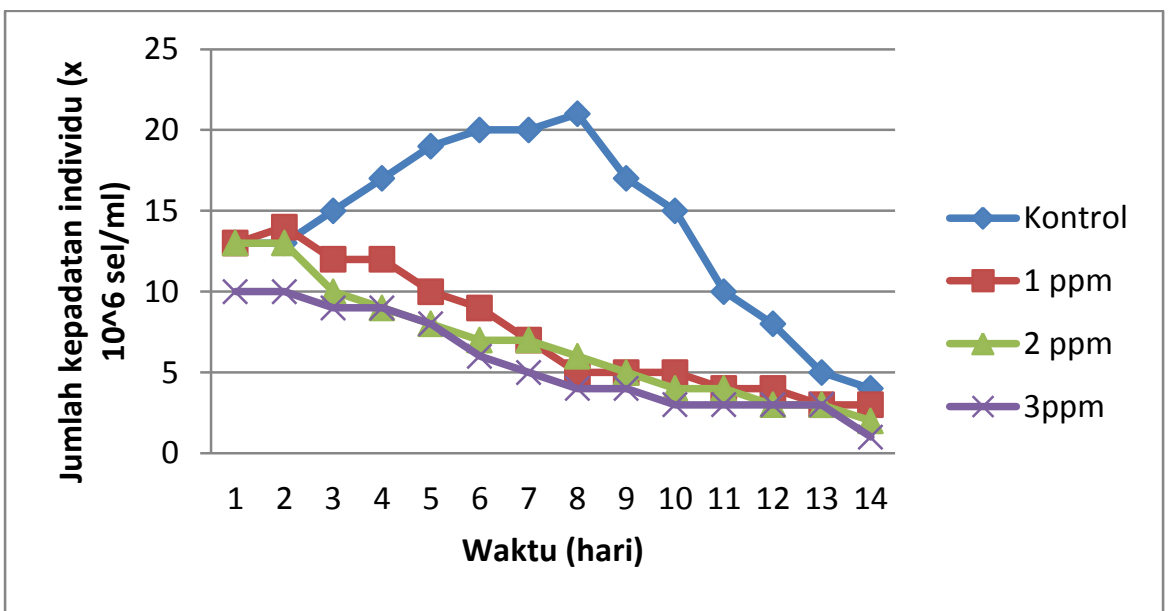

Gambar 2. Grafik Pertumbuhan D.salina Hari ke-14

penambahan sel-sel. Penambahan jumlah sel mulai terjadi pada hari yang ke tiga pada wadah kontrol yang berarti proses pembelahan sel yang terjadi mulai optimal. Wada $h$ yang sudah diberi dengan senyawa timbal sudah mulai mengalami penurunan pada hari ke 3. Pengamatan dilakukan sampai kepadatan sel mengalami fase kematian yaitu pada hari ke 14 kemudian dilakukan ekstraksi sampel tahap ke dua

\section{Analisis Ekstrak Pigmen Total dari Dunaliella salina Hari ke 8}

Hasil ekstraksi sampel alga kontrol dalam petroleum eter memiliki warna sampel yaitu kuning kehijauan. Serapan spektrofotometer membentuk puncak gelombang seperti terlihat pada Gambar 3. Berdasarkan hasil serapan spektrogram terlihat bahwa ekstrak pigmen total membentuk dua puncak gelombang yaitu pada panjang gelomban 415 dan 669, dengan konsentrasi pigmen klorofil a $0,71 \mu \mathrm{g} / \mathrm{ml}$ dan klorofil b $0,47 \mu \mathrm{g} / \mathrm{ml}$.

Hasil ekstrak sampel alga yang diberi larutan uji $\mathrm{Pb}$ Asetat $1 \mathrm{ppm}$ menghasilkan warna sampel ekstrak yaitu kuning kehijaun, hasil serapan spektrofotometer memperlihatkan bentuk spektrogram seperti yang ditampilkan pada Gambar 3. Pada hasil spektrogram membentuk puncak serapan maksimum pada panjang 
gelombang 417 dan $668 \mathrm{~nm}$, dengan konsentrasi pigmen klorofil a $0,69 \mu \mathrm{g} / \mathrm{ml}$ dan klorofil b $0,30 \mu \mathrm{g} / \mathrm{ml}$.

Hasil ekstraksi sampel alga yang diberi larutan uji $\mathrm{Pb}$ Asetat 2 ppm menghasilkan warna sampel ekstrak kuning kehijaun, hasil serapan spektrofotometer menapakan spektrogram seperti yang ditampilkan pada Gambar 3. Hasil penampakan spektrogram pada Gambar 3 diasumsikan masih terdapat kandungan pigmen yang masih tercampur. Puncak gelombang yang diperoleh terdapat pada kisaran panjang gelombang antara $418 \mathrm{~nm}$ dan $668 \mathrm{~nm}$, dengan

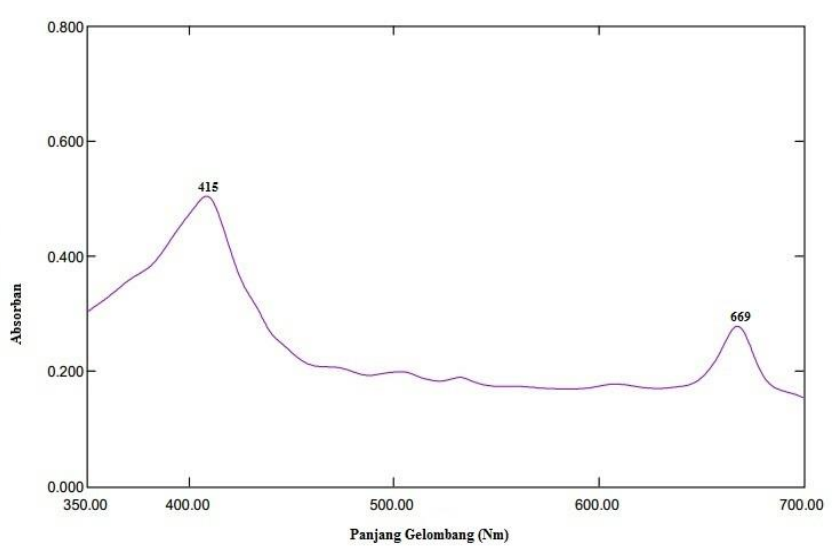

Kontrol

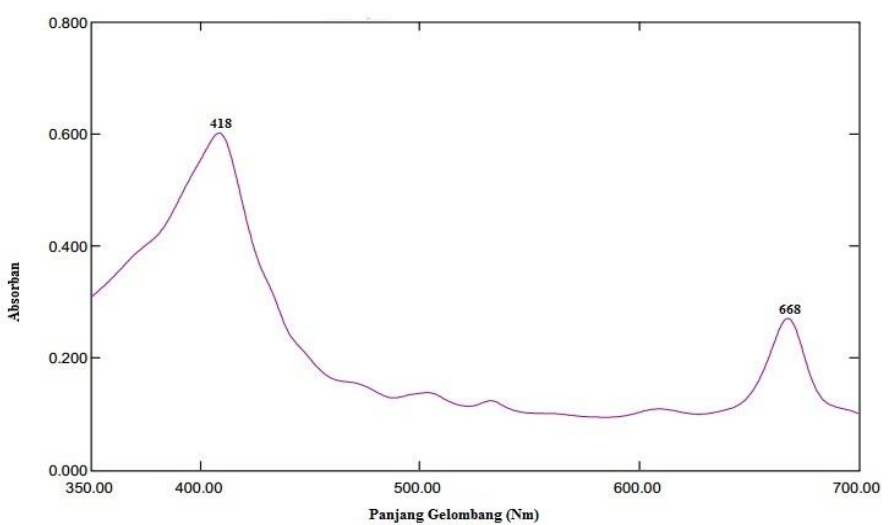

$2 \mathrm{ppm}$ konsentrasi pigmen klorofil a $0,67 \mu \mathrm{g} / \mathrm{ml}$ dan klorofil b $0,22 \mu \mathrm{g} / \mathrm{ml}$.

Hasil ekstrak sampel yang diberi larutan uji $\mathrm{Pb} 3$ ppm, menghasilkan warna sampel ekstrak yaitu kuning kehijauan, hasil serapan spektrofotometer manampakan spektrogram seperti yang ditampilkan pada Gambar 3. Pada Gambar 3 diasumsikan masih ada percampuran pigmen yang terdapat pada ekstrak alga, Puncak gelombang yang dihasilkan pada panjang gelombang 417 dan $668 \mathrm{~nm}$, dengan konsentrasi pigmen klorofil a $0,40 \mu \mathrm{g} / \mathrm{ml}$ dan klorofil b $\quad 0,13 \quad \mu \mathrm{g} / \mathrm{ml}$.
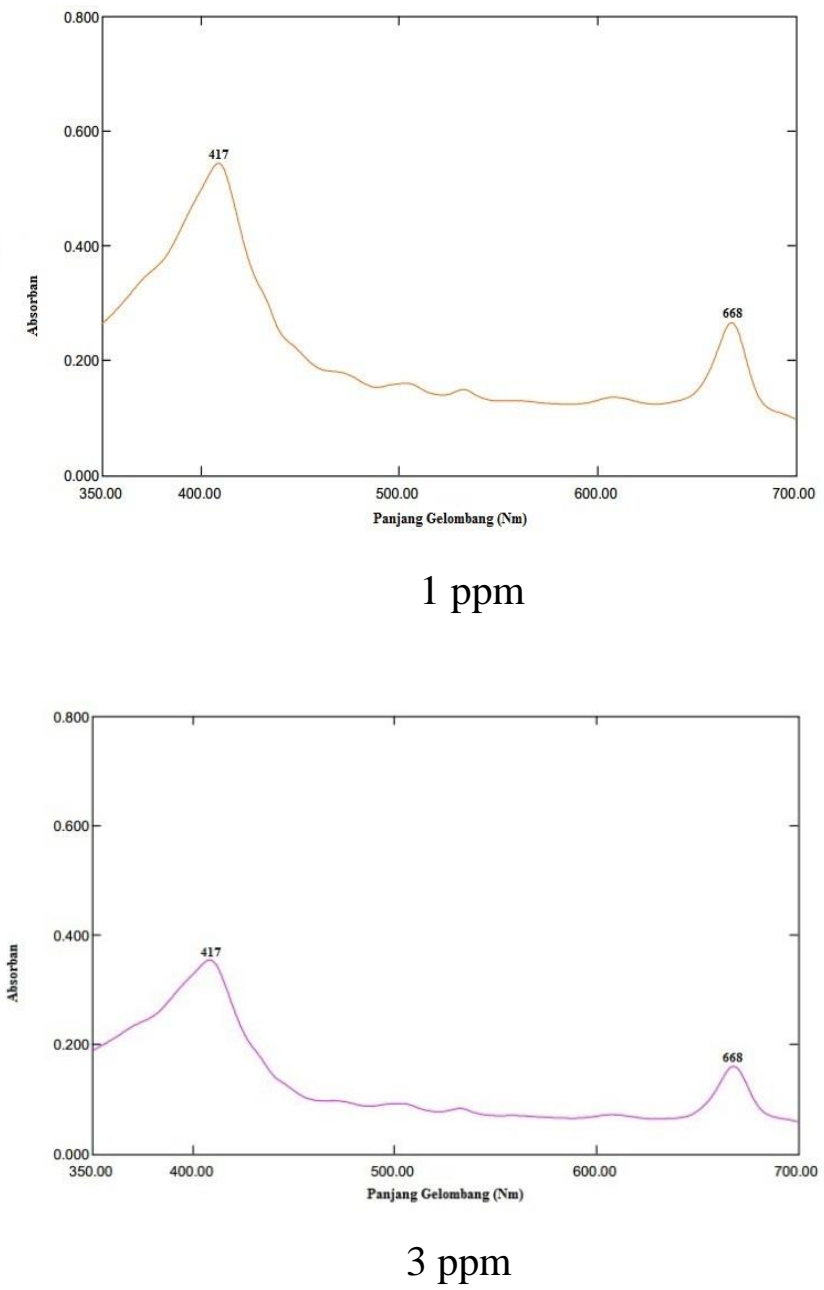

Gambar 3. Spektrogram ekstrak pigmen total hari ke-8 


\section{Analisis Pigmen Total dari Dunaliella salina hari ke 14}

Hasil ekstraksi sampel alga kontrol dalam petroleum eter memiliki warna sampel yaitu bening kekuningan. Hasil serapan

spektrofotometer memperlihatkan bentuk spektrogram seperti yang ditampilkan pada Gambar 4. Puncak gelombang yang dihasilkan pada panjang gelombang 415 dan 667 $\mathrm{nm}$, dengan konsentrasi pigmen klorofil a $0.11 \mu \mathrm{g} / \mathrm{ml}$ dan klorofil b $0,10 \mu \mathrm{g} / \mathrm{ml}$.

Hasil ekstraksi sampel alga pada larutan uji $\mathrm{Pb}$ asetat $1 \mathrm{ppm}$ dalam

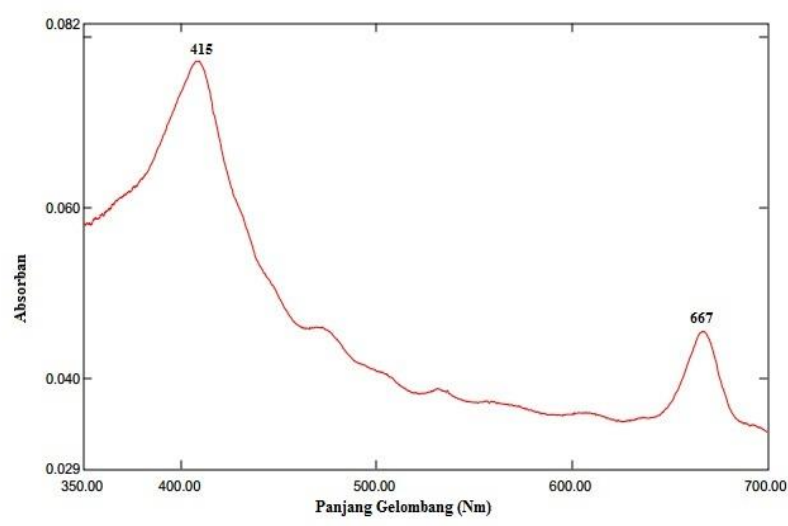

kontrol

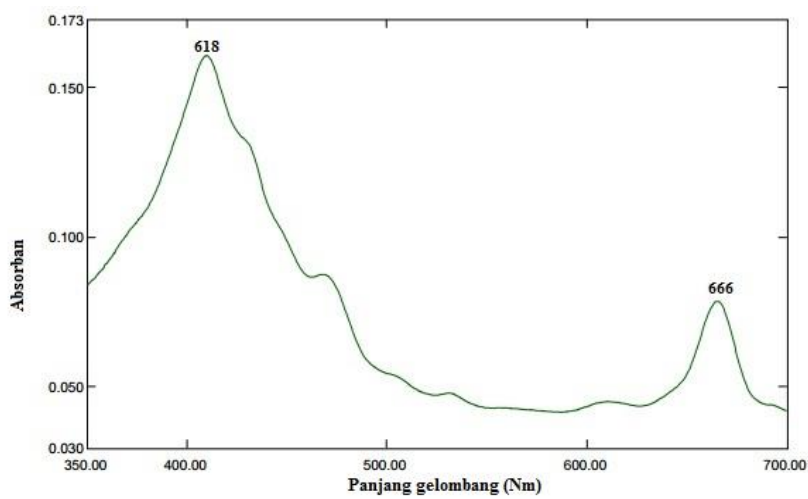

$2 \mathrm{ppm}$ petroleum eter memiliki warna sampel yaitu bening. Pada Gambar 4 masih ada pigmen yang terdapat pada alga walaupun warna ekstrak sudah menjadi bening. Puncak gelombang yang dihasilkan pada panjang gelombang 414 dan $667 \mathrm{~nm}$, dengan konsentrasi pigmen klorofil a $0,16 \mu \mathrm{g} / \mathrm{ml}$ dan klorofil b $0,13 \mu \mathrm{g} / \mathrm{ml}$.

Hasil ekstraksi sampel alga pada larutan uji $\mathrm{Pb}$ asetat $2 \mathrm{ppm}$ dalam petroleum eter memiliki warna sampel yaitu bening seperti pada larutan uji 1 ppm. Pada Gambar 4 masih ada

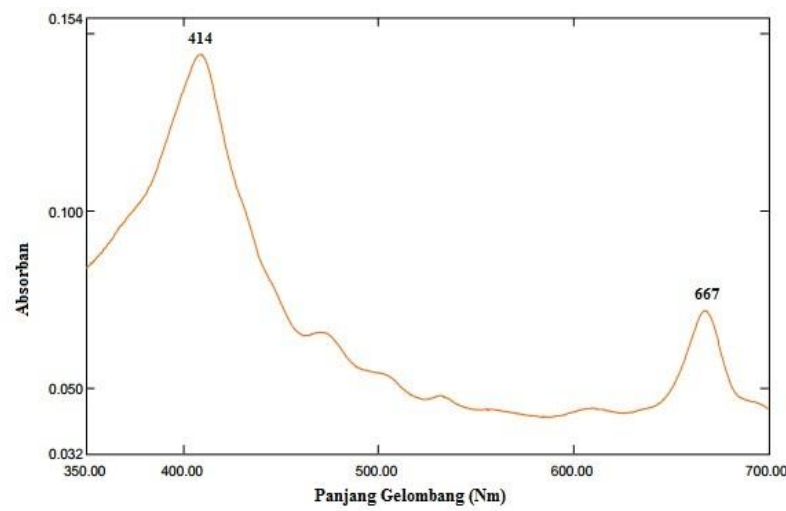

1 ppm

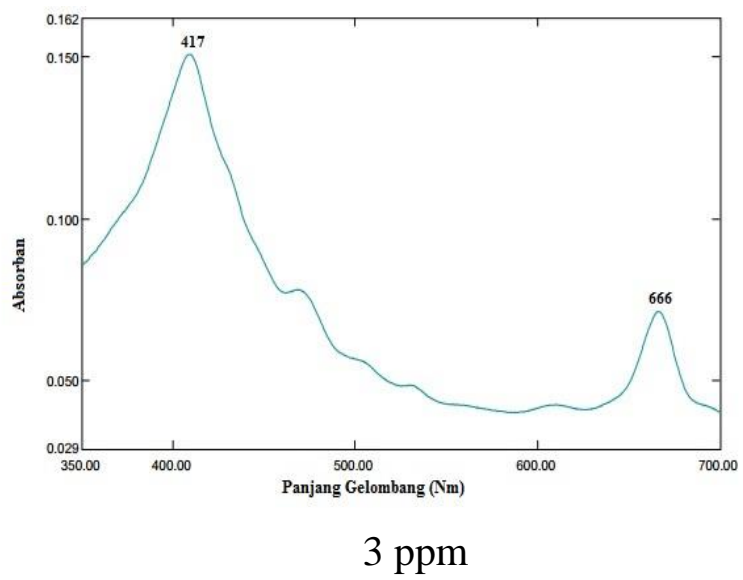

Gambar 4. Spektrogram ekstrak pigmen total hari ke-14 
pigmen yang terdapat pada ekstrak alga walaupun warna ekstrak sudah menjadi bening seperti pada larutan uji 2 ppm. Puncak gelombang yang dihasilkan pada panjang gelombang 418 dan $666 \mathrm{~nm}$, dengan konsentrasi pigmen klorofil a $0,20 \mu \mathrm{g} / \mathrm{ml}$ dan klorofil b $0,14 \mu \mathrm{g} / \mathrm{ml}$.

Hasil ekstraksi sampel alga pada larutan uji $\mathrm{Pb}$ asetat $3 \mathrm{ppm}$ dalam petroleum eter masih memiliki warna sampel yaitu menjadi bening seperti pada larutan uji 1 dan 2 ppm. Puncak gelombang yang dihasilkan pada panjang gelombang yaitu 417 dan 666 $\mathrm{nm}$, dengan konsentrasi pigmen klorofil a $0,18 \mu \mathrm{g} / \mathrm{ml}$ dan klorofil b $0,13 \mu \mathrm{g} / \mathrm{ml}$.

\section{Berdasarkan perhitungan} konsentrasi pigmen klorofil a dan klorofil b didapatkan bahwa konsentrasi pigmen klorofil a dan klorofil b pada hari ke 8 lebih tinggi dibandingkan dengan konsentrasi pigmen klorofil a dan klorofil b pada hari ke 14. Pada hari ke 8 konsentrasi pigmen klorofil $a$ dan $b$ pada kontrol lebih tinggi dari pada konsentrasi klorofil pada ekstrak yang diberi timbal pada konsentrasi 1 ppm, 2 ppm, dan 3 ppm. Berbeda dengan konsentrasi klorofil a dan klorofil b pada ekstrak hari ke 14, wadah kontrol lebih rendah konsentrasi pigmen klorofil dibandingkan dengan ekstrak yang diberi senyawa timbal. Hal ini diasumsikan bahwa mikro alga $D$. salina yang diberi senyawa timbal mampu mempertahankan hidupnya dengan cara meningkatkan konsentrasi kandungan pigmen klorofil.

\section{Analisis Kromatografi Lapis Tipis}

Pada ekstrak pigmen total dalam petroleum eter alga hijau $D$. salina yang diperoleh masih menujukan adanya suatu percampuran pigmen, sehingga masih perlu diadakan satu analisis dengan menggunakan teknik Kromatografi Lapis Tipis.

Pada larutan pengembang 80:20 terjadi 6 pemisahan fraksi pigmen, kromatogram hasil

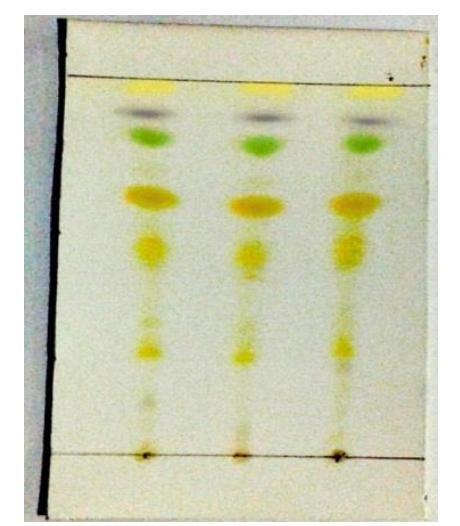

Fraksi 1

Fraksi 2

Fraksi 3

Fraksi 4

Fraksi 5

Fraksi 6

Gambar 5. Kromatogram hasil migrasi ekstrak pigmen total dengan pengembang PE : Aseton (80:20)

pengembangan dapat dilihat pada Gambar 5.

\section{Fraksi 1}

Hasil analisis isolasi pada fraksi 1 membentuk puncak pada panjang gelombang 439, 465 dan 551 yang menampilkan bentuk kurva serapan, seperti yang tampak pada Gambar 6 . Menurut Britton and Pfander (1995) identifikasi berdasarkan ke-3 puncak maksimum didapatkan jenis pigmen $\beta$ karoten untuk pigmen hasil isolasi fraksi 1.

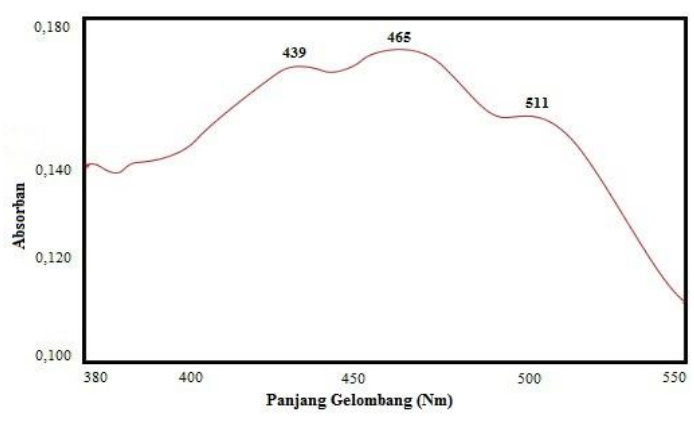

Gambar 6. Bentuk kurva pigmen $\beta$ karoten fraksi 1

\section{Fraksi 2}

Hasil analisis kromatografi lapis tipis fraksi 2 menghasilkan warna abuabu, pigmen ini dianalisis menggunakan spektrofotometer dan membentuk 2 puncak pada panjang 


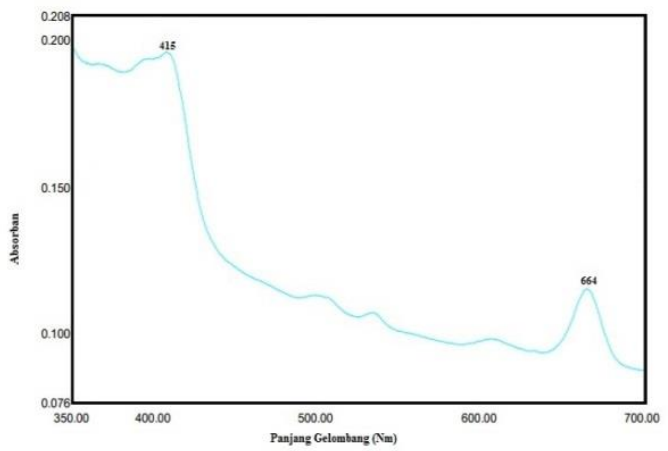

Gambar 7. Bentuk kurva pigmen feofitin a fraksi 2

gelombang 415 dan 664. Berdasarkan identifikasi menurut Goodwin (1988) 2 puncak yang terbentuk di dapatkan jenis feofitin a.

\section{Fraksi 3}

Pigmen pada fraksi 3 setelah dimigrasi tampak berwarna hijau muda, setelah diisolasi pigmen fraksi 3 ini dianalisis dengan spektrofotometer dan didapatkan 2 puncak gelombang yaitu 413 dan $667 \mathrm{~nm}$ menunjukan adanya kandungan klorofil a. Menurut Goodwin (1988) pigmen yang terkandung adalah dari jenis pigmen klorofil a.

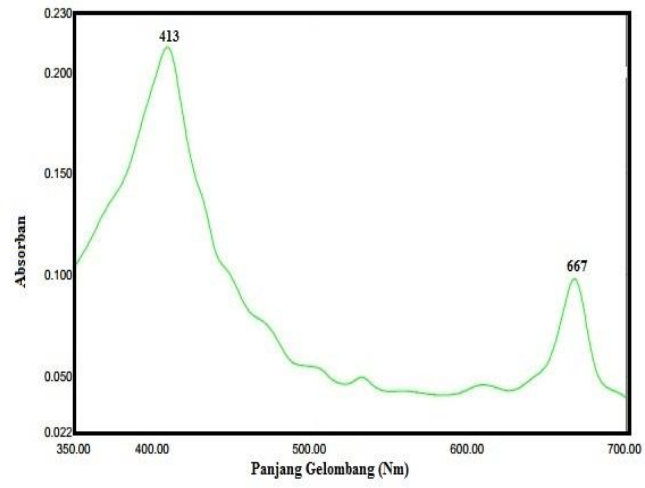

Gambar 8. Bentuk kurva pigmen klorofil a fraksi 3

\section{Fraksi 4}

Hasil isolasi ekstraksi pigmen dari kromatografi lapis tipis menampilkan warna kuning tua dan setelah dianalisis dengan spektrofotometer pada panjang

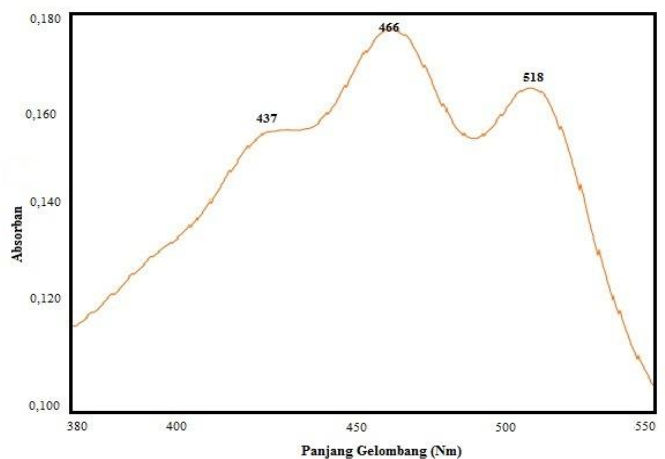

Gambar 9. Bentuk kurva pigmen tipe zeaxanthin fraksi 4.

gelombang 380-550 nm menujukan 3 puncak utama yaitu pada panjang gelombang 437, 466 dan 518 nm menunjukkan adanya pigmen tipe zeaxanthin.

\section{Fraksi 5}

Fraksi 5 didapatkan warna kuning muda dan setelah dianalisis menggunakan spektrofotometer diperoleh 3 puncak pada panjang gelombang 420, 478 dan 530. Menurut Britton dan Pfander (1995) pada fraksi 5 ini teridentifikasi sebagai pigmen tipe alloxantihin.

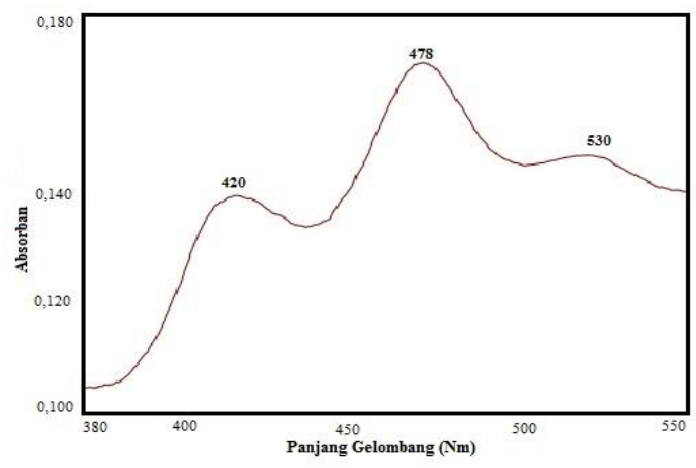

Gambar 10. Bentuk kurva pigmen tipe alloxanthin fraksi 5

\section{Fraksi 6}

Fraksi 6 berada pada pada Rf 0,23 dengan warna kuning muda dan tidak dapat teridentifikasi jenis pigmennya karena pada waktu pengisolasian sudah terjadi penguapan sehingga tidak dapat teridentifikasi.

Hasil dari analisis kromatografi lapis tipis diatas menujukan ada 4 fraksi 
dengan warna kuning, hal ini disebabkan karena pada mikro alga $D$. salina memiliki pigmen karotenoid yang melipah. Menurut Avron (1992) mengatakan bahwa Dunaliella memiliki gelembung-gelembung karoten yang melimpah dan tersebar dalam selnya. jadi dapat disimpulkan bahwa walaupun jumlah populasi menurun diakibatkan logam berat tapi masih terdapat kandungan pigmen.

\section{KESIMPULAN}

Pemberian senyawa timbal asetat dapat menurunkan konsentrasi pigmen pada ekstraksi hari ke 8, Namun pada konsentrasi pigmen klorofil pada ekstraksi hari ke 14 meningkat pada wadah yang diberi dengan senyawa timbal. Hal ini dikarenakan pada wadah hari ke $14 D$. salina mempertahakan hidup dengan meningkatkan konsentrasi pigmen klorofil. Hasil dari analisis kromatografi lapis tipis menujukan ada 3 fraksi dengan warna kuning, yaitu fraksi 1 dengan jenis Pigem $\beta$-karoten, fraksi 4 dengan jenis pigmen tipe zeaxanthin dan fraksi ke 5 dengan jenis pigmen tipe alloxanthin.

\section{DAFTAR PUSTAKA}

Avron, M., Ben-Amotz. A. 1992. Dunaliella : Physiology, Biochemical, and Biotechnology. CRC Press, Inc.

Bold, H., Wynne. 1985. Introduction To The Alga. Pretice, Inc. England.

Britton, G.S., Pfander. H. 1995. Carotenoids. Volume IB. Spectroscopy. Basel. Switzerland.

Evo, T. 2001. Pengertian Laut, Macam Laut \& Manfaat Laut . Diakses 30 April 2015, dari http://www.organisasi.org/1970/ 01/definisi-pengertian-laut-jenis macam-laut-fungsi-peranmanfaat-laut.html.

Goodwin, T.W. 1980. The Biochemistry of The carotenoid. Second edition. Chapman Hall Inc. London.

Goodwin, T.W. 1988. Plant Pigmen. Academis Press Limited. London.

Harborne, J.B.1987. Metode fitokimia : Penuntun Cara Modern Menganalisis Tumbuhan. ITB. Bandung.

Jupin, H., Lamant. A. 1999. La Photosynthese. Dunod. French.

Ratri, G.A., Rohman. F., Saptasari. M. 2003. Struktur Komunitas Makroalga Di Pantai Ngudel. Universitas Negeri Malang.

Wijaya, L.N. 2004. Fingsi Biologis karotenoid. Makalah dalam Bidang Toksikologi dan farmsitika laut Fakultas Perikanan dan IImu kelautan Universitas Sam Ratulangi.

Wong, S.L.,Wainwright., Pimenta. J. 1995. Aquatic Toxicology. Elsevier Science Inc; USA. 